\title{
Developing a Comprehensive Library Management System for Tamale Polytechnic
}

\author{
Abukari Abdul Aziz Danaa \\ Dept. of Computer Science \\ Tamale Polytechnic \\ Tamale, Ghana.
}

\author{
Mumin Diyawu \\ Dept. of Computer Science \\ Tamale Polytechnic \\ Tamale, Ghana.
}

\begin{abstract}
The numerous problems of borrowing and returning books and maintaining comprehensive user profiles in the Tamale Polytechnic's library using the current manual system is seriously affecting the overall productivity of the facility. The impact of which is the poor and inefficient delivery of service to members. Since issuing of books is done by several librarians, details of which librarian issued or received a borrowed book is always not accurate and can easily be manipulated by individuals with their personal interests. A successful solution would be a computerized System for monitoring all transactions, members, user accounts, keep proper records of login details of users as well as effective generation of reports. All transactions that occur within the library are recorded automatically. It also has a fine and ad-hoc report generation mechanisms.
\end{abstract}

Keywords: successful; computerised; automatically; problems; transactions

\section{INTRODUCTION}

The proposed System is automated for managing the activities of the Tamale Polytechnic library. It is a secured system where only authenticated users are allowed access into it using a password protection mechanism. If a user fails to login successfully after three attempts, that particular user's account is locked. It is only the administrator who can unlock that user. Another significant security feature about the system is its ability to automatically record the date and time a particular user logs in and out the system. The system keeps records of all media and members of the library. All transactions that occur in the library are recorded automatically. It also has a fine generation mechanism as well as ad-hoc report generation feature.

\section{OBJECTIVES OF THE PROPOSED SYSTEM}

The proposed System is automated for managing the activities of the polytechnic library. Such system must be very secured whereby the software can be accessed only by the authenticated user using the password protection mechanisms.[1] If a user fails to login after three attempts, that particular user's account is locked. It is only the administrator who can unlock that user. Another significant security feature about the system is its ability to automatically record the date and time a particular user logs in and out the system.

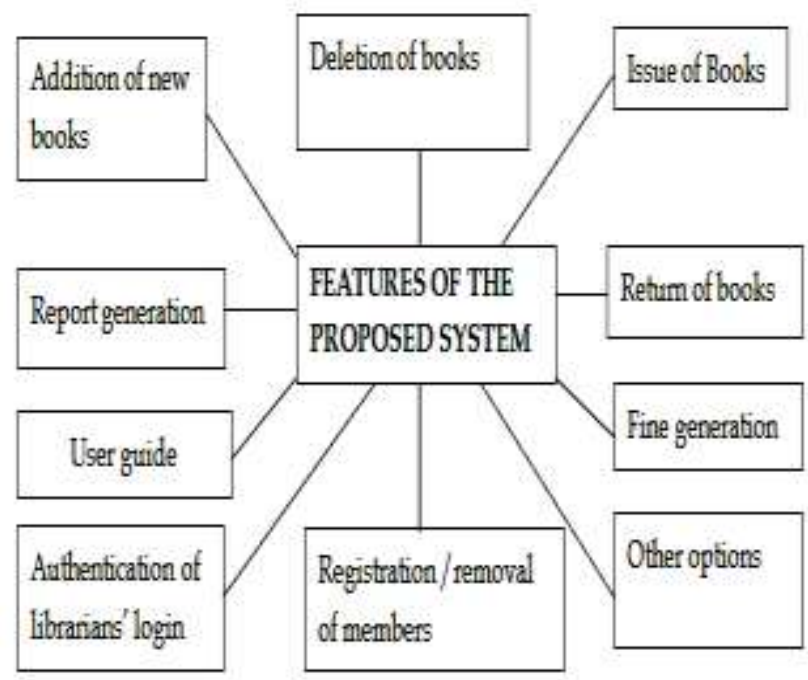

Figure 1 Objectives of the proposed system

\section{BASIC THEORY}

\subsection{Programming Language Used}

The project employed Visual Basic .NET (VB.NET) which is an object-oriented programming language which is a transformation of the classic Visual Basic (VB) developed on the .NET Framework. The .NET Framework is software that runs primarily on Microsoft Windows.[2] It includes a large library and supports each language using codes written in other languages. 


\subsection{SQL Server 2005}

Microsoft SQL Server 2008 is the database backend for the library Management system. It includes native support for handling XML and relational data. For this reason, it defines an $\mathrm{xml}$ data type that could be used either as a data type in database columns or literals in queries.[4] Columns in XML can be associated with XSD schemas; data in XML is being stored is authenticated against the schema.

\section{SYSTEM DESIGN}

\subsection{Analysis of Existing Project Management System}

Currently, almost all transactions in the Tamale Polytechnic library system is done manually.

Main features of the current system are:

$>$ Large volume of books and student's data are maintained in the form of registers

$>\quad$ Issue Procedure: A Student can be issued three (3) books at a time using the allotted issue cards to him. The librarian takes off the book card from the book in which all the details of the book are written. $\mathrm{He}$ attaches the book card with the issue card of the student and places it in the record column.

It is to be noted that the issue card has to be placed in the sorted fashion, sorted in columns by class (i.e. Primary Key) and any sorting collisions are handled by sorting by secondary key i.e. the students Matric number.

$>$ Book return procedure: Student is required to return the book within the due date. the book is taken by the librarian then the issue card of that student is taken out from the sorted records (with the book card attached with the library issue card), then the book card is again placed in the respective book and the issue card is returned to the student by cutting of his entry from the book card indicating that the student no longer holds that book with him. If the book is not returned within the due date then the fine is calculated.

$>$ In the course of adding new books, three registers are maintained by the library staff; Register of Authors, register of Books Title, Register of books sorted by accession number. These registers are needed as a catalogue for searching a particular book and determining whether it is present in library or not. New arrivals of the books are appended to books register and a notice is put up on the library notice board to inform the students about it.

$>$ Fine system: It is required by the librarian to calculate the fine which is paid by the student on not returning the book within the return date of the book. Librarian sees the issue book register and checks the issue date and return date along with the student's details. The cost of the fine is GH 2/day for a book and is calculated as the difference between the current date and the return date.

\subsection{Problems with the Current System}

$>$ No backup can be maintained as the data is large and duplication of data consumes lot of time.

$>$ Analysis on data and access to database is tedious.

$>$ Inability to obtain the status of a book rapidly.

$>$ Modification of the details of Student/Book is a large process and may lead to chaos and is prone to errors.

$>$ It is very difficult to search a particular book entry as all the book registers are looked which requires very large work force and is a tedious and cumbersome process.

\subsection{Data Flow Diagram (DFD)}

Data Flow Diagram (DFD) provides an indication of how data are transformed as they move through the system. It also depicts the function that transforms the data flow.[6][1]

\subsubsection{Context Diagram}

Context diagrams in DFD show the overall information and entity in an application.[6] This is presented below;

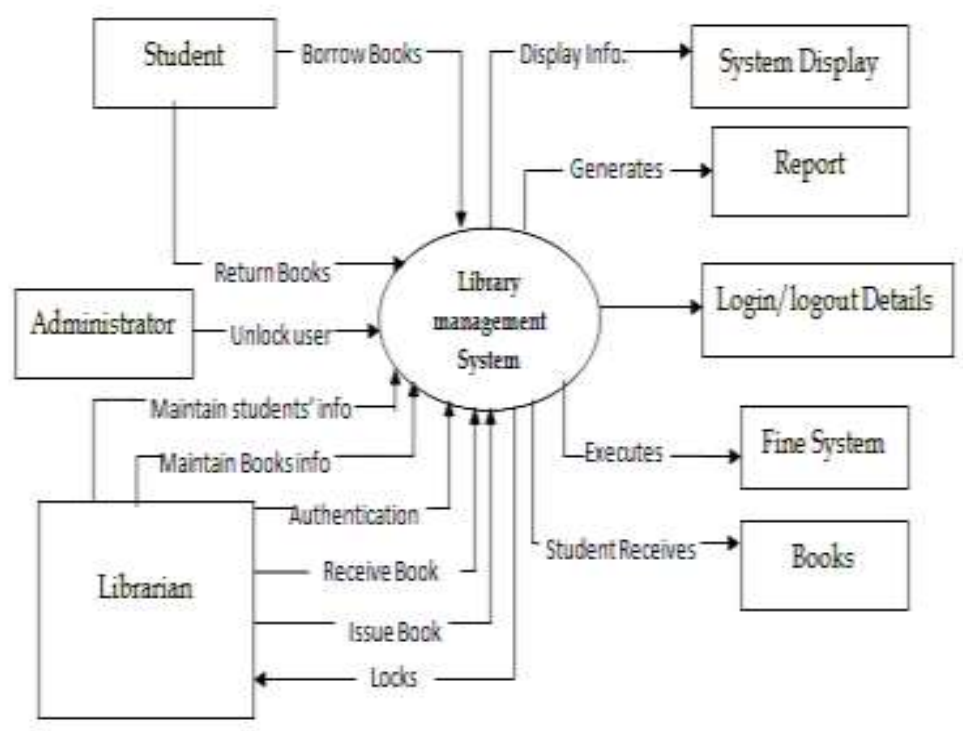

Figure 2 Context level DFD

\subsubsection{Level 1 DFD}

The Level 1 DFD outlines how the proposed system is divided into sub-systems (processes), each of which deals with one or more of the data flows to or from an external agent, and which together provide all of the functionality of the system as a whole. It also identifies internal data stores that must be present in order for the system to do its job, and shows the flow of data between the various parts of the system. [7][5] The figure below shows the level 1 DFD used for the system; 


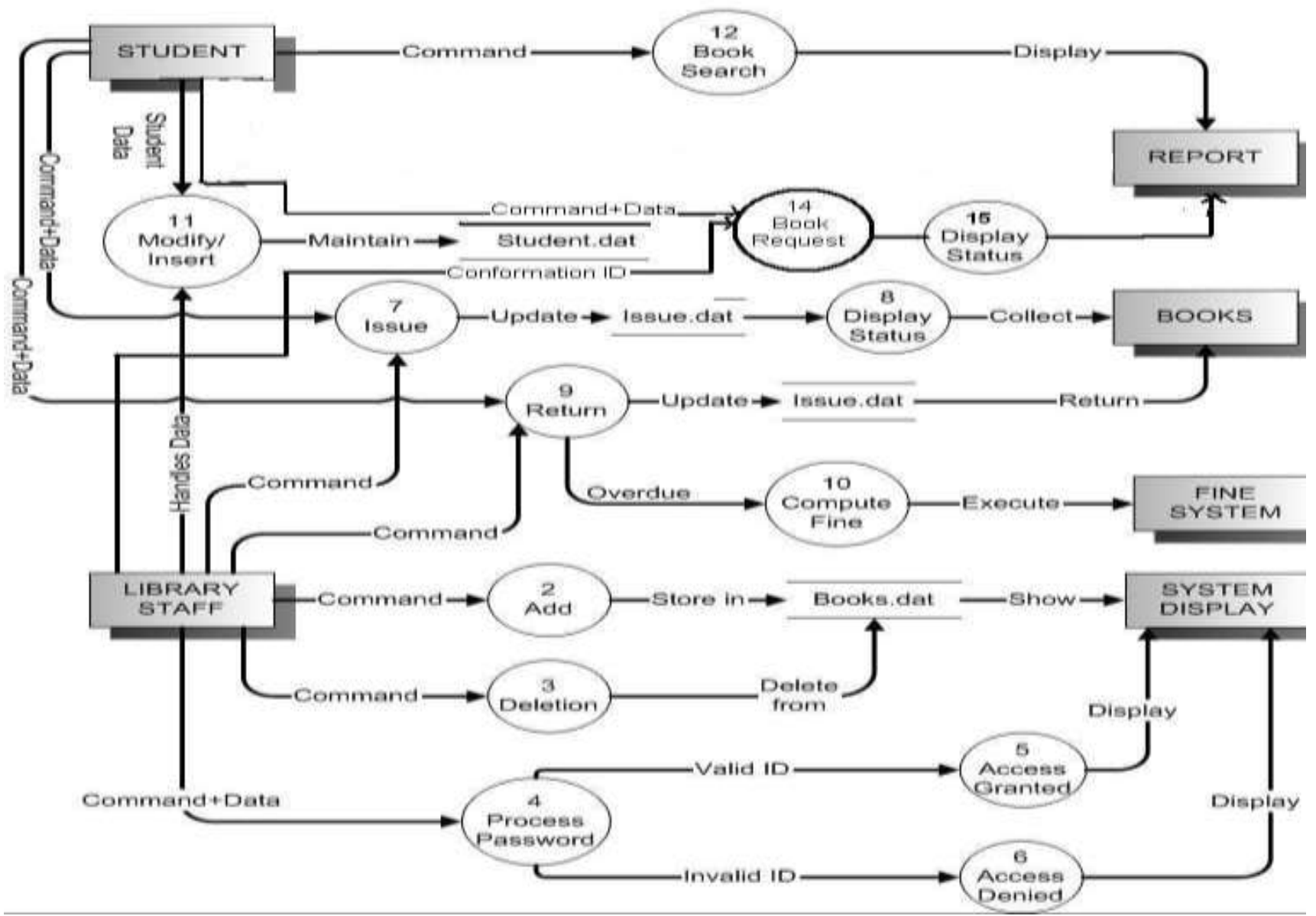

Figure 3 LEVEL 1 DFD

\subsection{Entity Relationship Diagram (ERD)}

The ERP specifies the relationships between data objects and attribute of each data object can be described using a data object description.[3][4]

The entity relationship model for the application can be seen in Figure 4 below. 


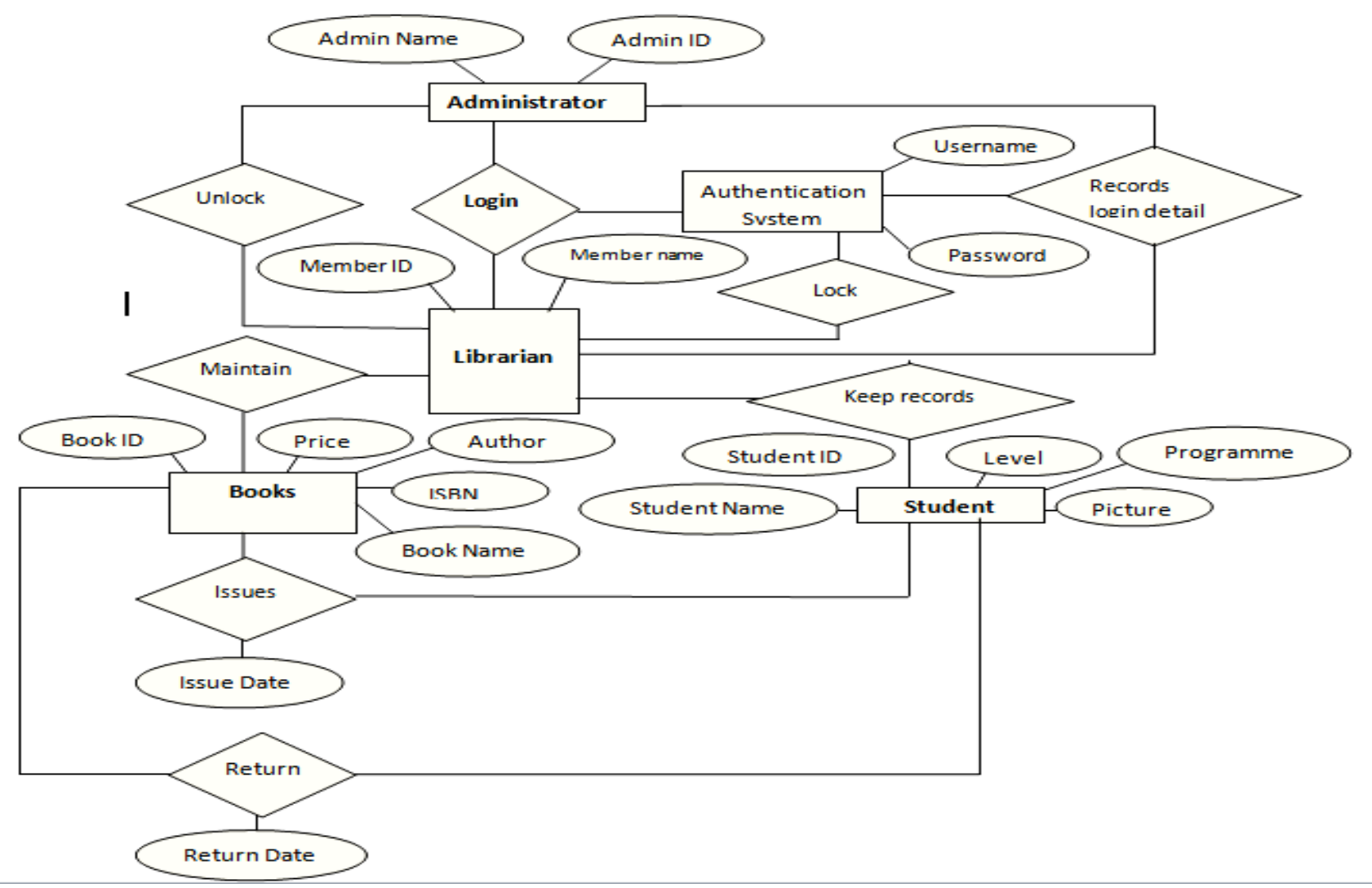

Figure 4 E-R Diagram of the Proposed System

\subsection{Application Implementation}

This section is divided into sub-sections in which each is going to feature a short explanation and a screenshot of the a particular feature of the proposed system .

\subsubsection{User authentication form}

A user provides a username and a password to login into the system. However if a user fails to login after three attempts, his/her account is locked automatically. At this point it is only the system administrator who can unlock the user and possibly reset the password. The system also records the date and time a particular user logins in and out the system. Fig. 5 below depicts that.

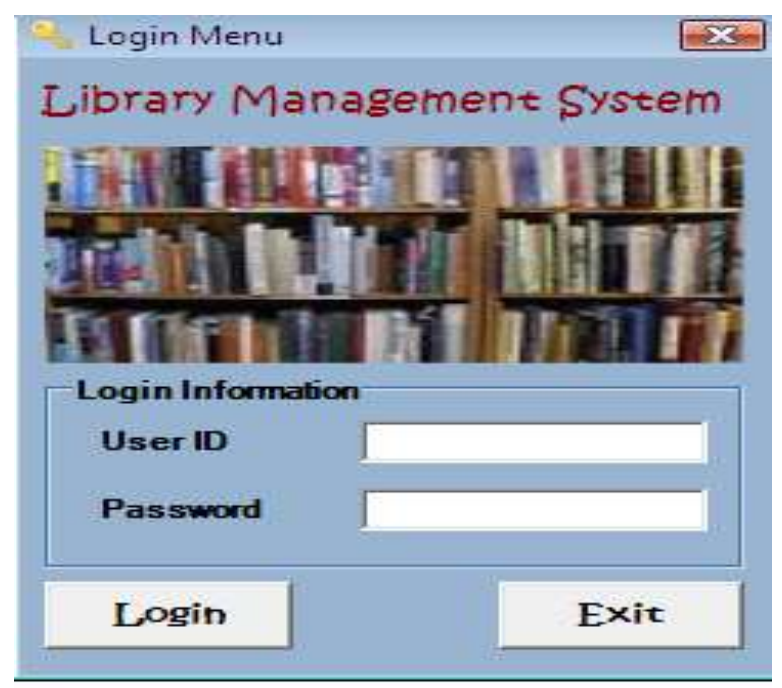

Figure 5 Login Form

\subsubsection{Book form}

Book Issuing Procedure: A Student can be issued a book provided it is available and not already issued to another student. Once the librarian clicks on the issue option, all the books available for borrowing are automatically displayed. The student ID is entered and all detail related information about the student appears. The librarian also clicks on the book the 
student wishes to borrow and automatically its detail information is also retrieved. The procedure checks for the case when the book is already issued to some other borrower or the book is not present in the library and thus the book is not available for issuing. The librarian does not need to enter the issuing date since the current date is automatically used and then the validations for the date are performed. However the return date will have to be entered by the librarian.

New arrivals of the books are appended to the books database and the number of books in the library is incremented by 1 . The screen shot in fig 6 below depicts that.

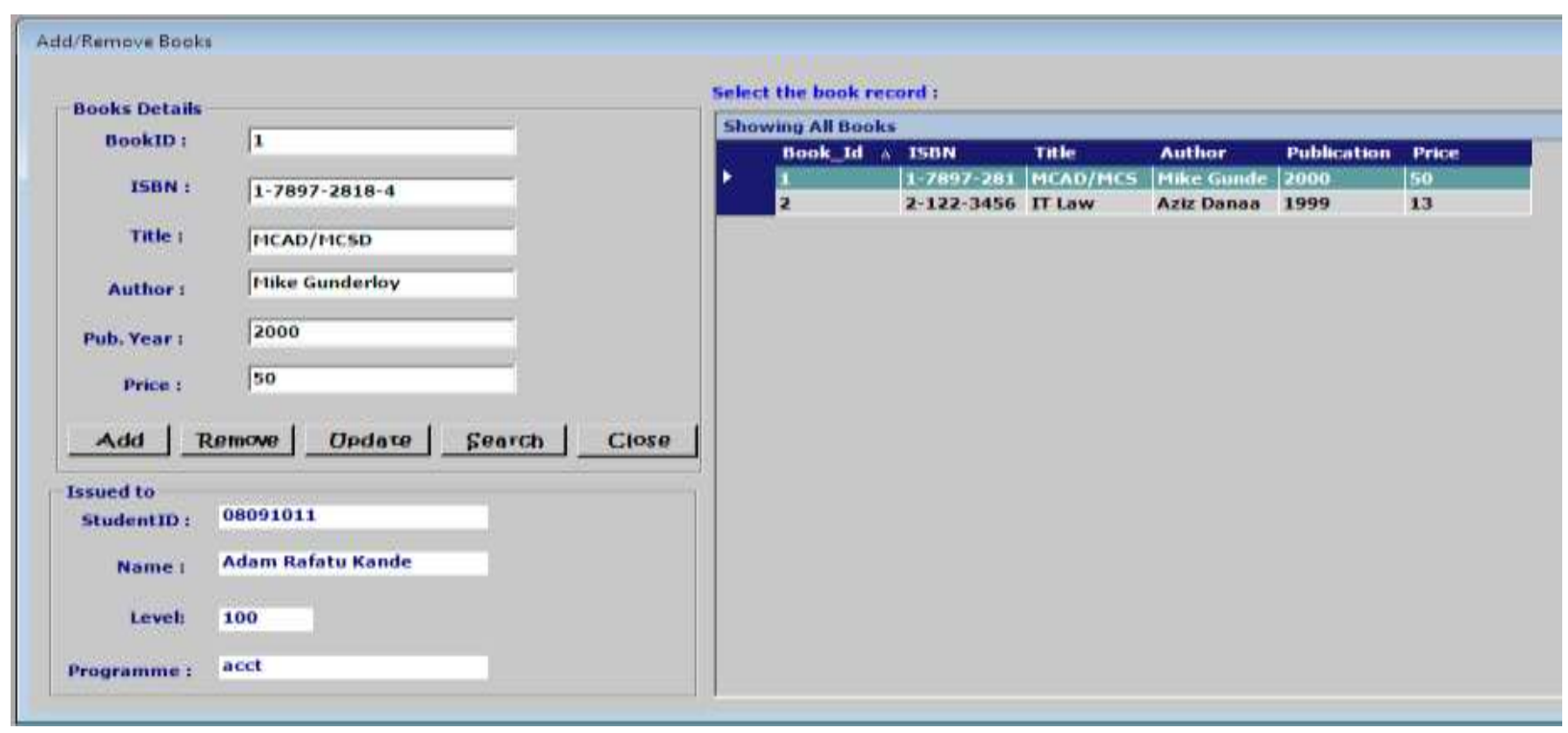

Figure 6 Books Form

\subsubsection{Students Form}

New student records are added to the database using the form in fig. 7 below, where the student is allowed to borrow up to a maximum of books specified by the systems administrator. Pictures of students are also captured to prevent impersonation.

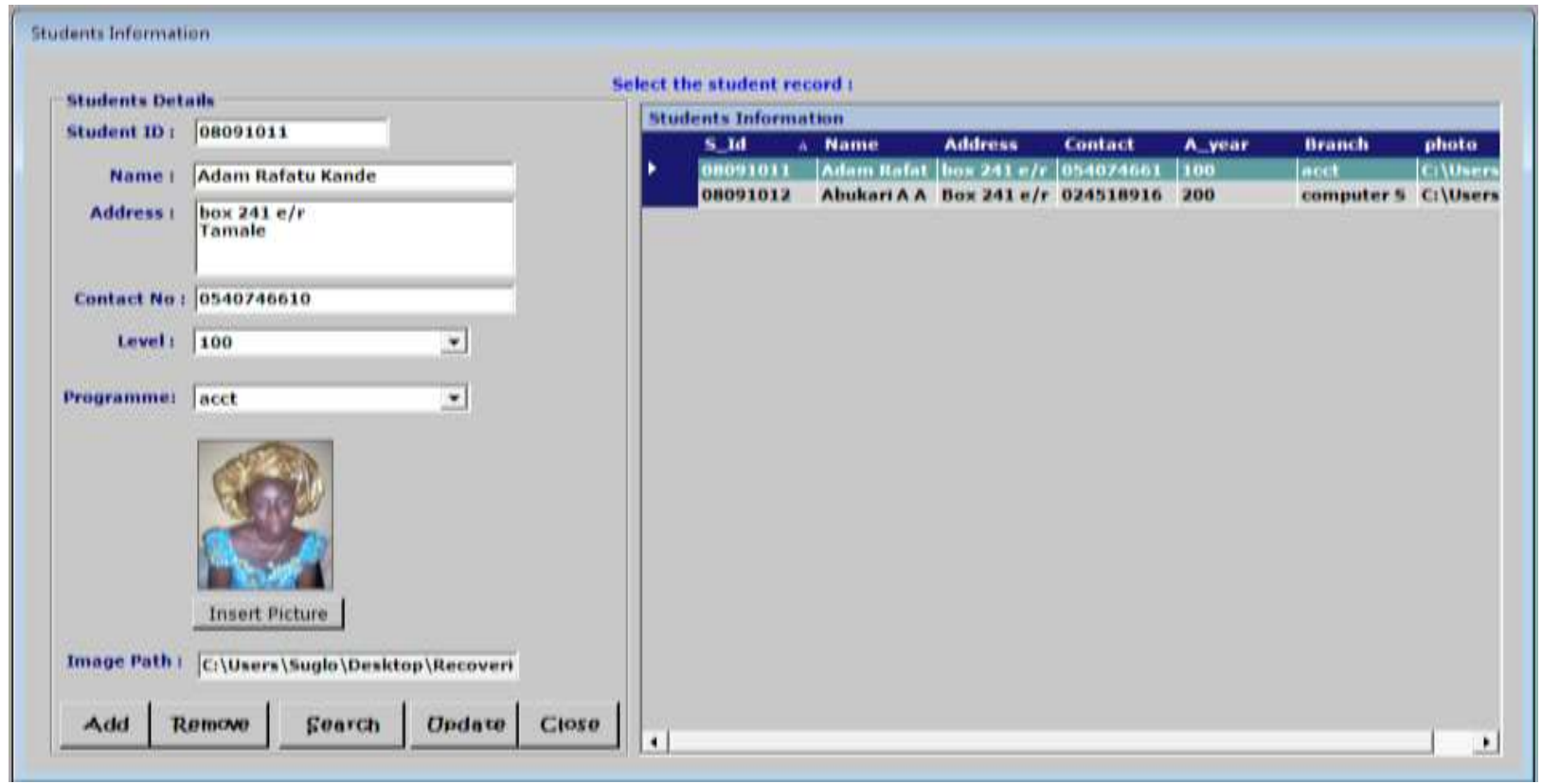

Figure7 Students form 


\subsubsection{Transaction Form (return Option)}

A Student is required to return the book before/on the due date otherwise he has to pay the fine which is calculated and generated by the system automatically based on the interval between the return date and the date of issuing. Once the librarian clicks on the Return option, all borrowed
Books are automatically displayed along with students currently keeping those books. The issued and return dates of those books are also displayed. The librarian clicks on the books to be returned and necessary information about the book and the student is retrieved. He then clicks on the return button and the book is returned. A screen shot is illustrated in the figure below;

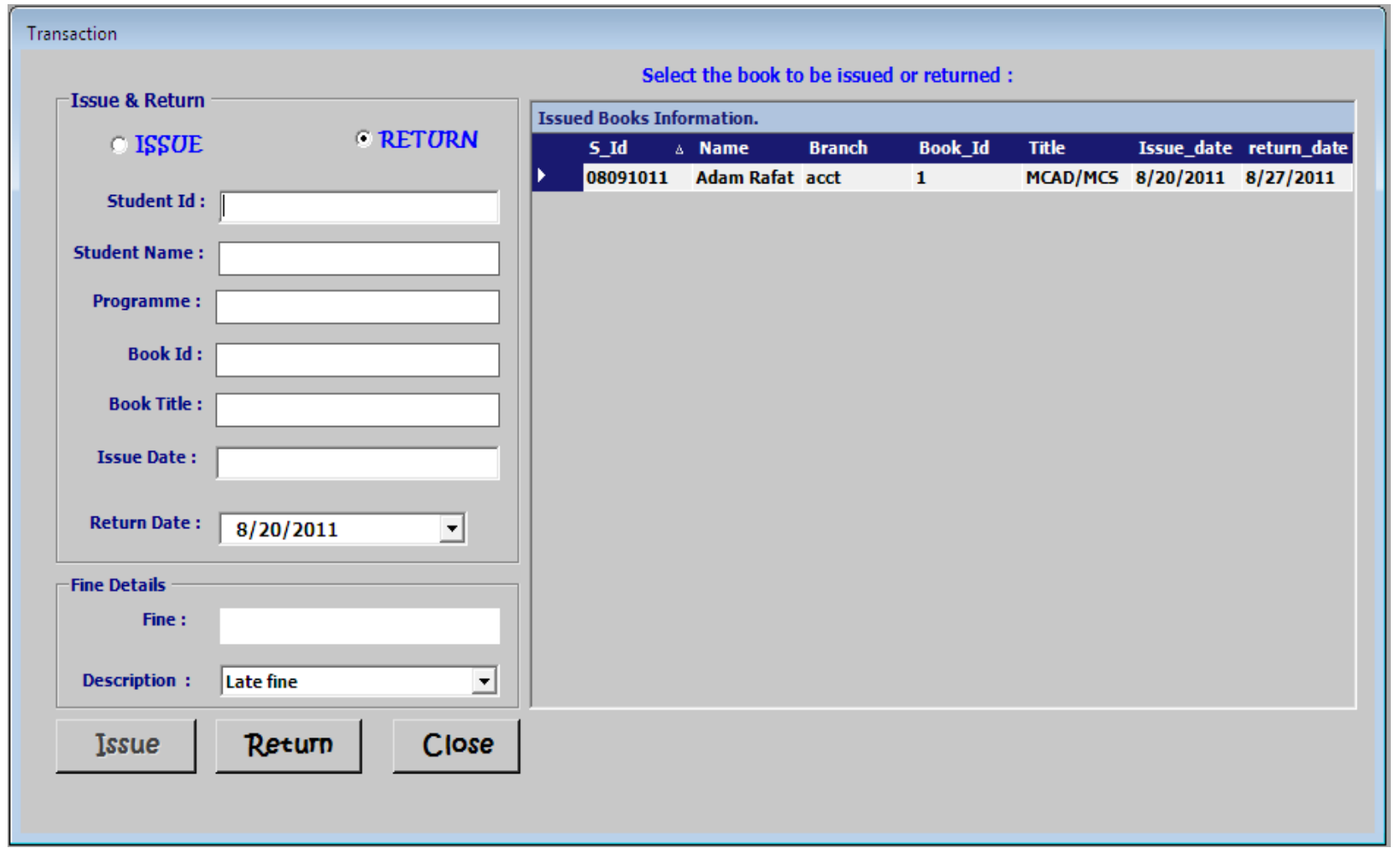

Figure 8 Transaction form

\subsubsection{Options Form}

The system generates a fine as prescribed by management of the library. The Return date of books is generated according to a predetermined time interval. If the book is not returned before the return date arrives then fine is automatically calculated and the student is charged to pay that amount. Figure 9 below shows how the fine and the number of books a student can borrow at a time is determined.

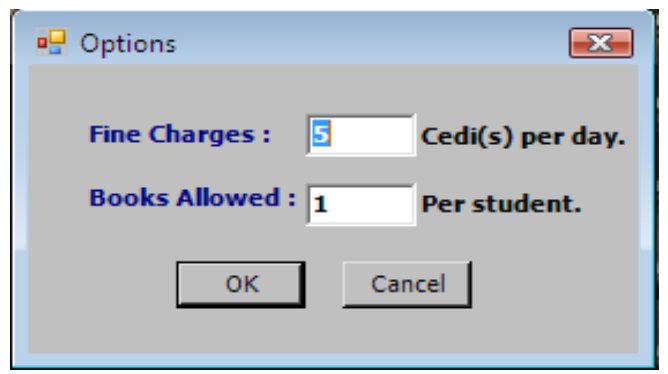

Figure 9 Options form

\subsubsection{Report generation}

The system incorporates report generation and filtering mechanisms. Reports can be built on the basis of the following criteria:

$\checkmark \quad$ List different books present in the library with the columns separated under different fields viz. Author name, Edition number, category, ISBN, Book ID and status of the book whether the book is issued or not.

$\checkmark \quad$ View the details of books currently issued.

$\checkmark$ View the books present in the library that is the books which have not been issued by any of the borrowers.

$\checkmark$ Details of students who are currently issued books with the details of the books.

$\checkmark$ Fine report

$\checkmark \quad$ A detailed log report of users.

Figure 10 below shows a sample report of current students in the library; 


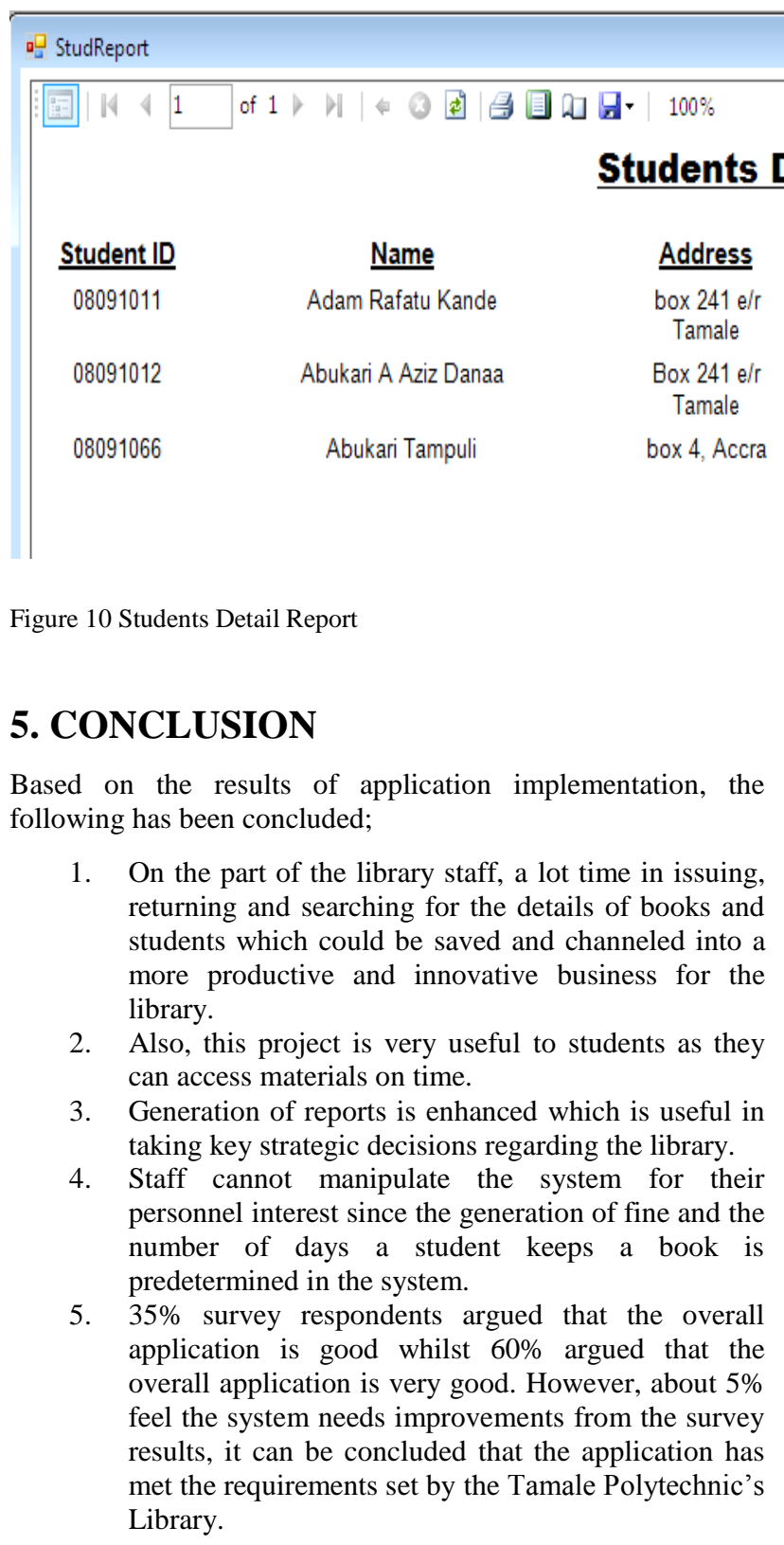

\section{REFERENCES}

[1] Kemp, S. (2006). Project Management Made Easy. California: Entrepreneur Press.

[2] Lucas and Serpa Silva, "Evolutionary Testing of Object-Oriented Software" ACM SAC'10, March 22- 26, 2010, Sierre, Switzerland, 978-160558-638- 0/10/03

[3] Mauro Pezze and Michal Young, "Testing Object Oriented Software", IEEE Proceedings of the 26th international conference on Software Engineering(ICSE' 04).

[4] Qureshi, M. \& Sabir, F. 2013. A Comparison Model View Controller and Model View Presenter. Sci.Int.(Lahore), 25(1):7-9.

[5] Kalelkar, M., Churi, P., Kalelkar, D. 2014. Implementation of Model-View-Controller Artchitecture Pattern for Business Intelligence Architecture. International Journal of Computer Applications, 102(12):16-21.

[6] Data Flow Diagram (DFD)s: An Agile Introduction. Retrieved May 29, 2016. http://www.agilemodeling.com/artifacts/dataFlo wDiagram.htm

[7] Roger S. Pressman, Software Engineering A Practitioner's Approach, Seventh Edition, McGrawHill Int'l Edition. 